\title{
Magnetic Fields for Electropolishing Improvement: Materials and Systems
}

\author{
Tadeusz Hryniewicz ${ }^{1, \star}$, Krzysztof Rokosz ${ }^{1}$, Ryszard Rokicki ${ }^{2}$ \\ ${ }^{1}$ Surface Electrochemistry Division, Koszalin University of Technology, \\ Raclawicka 15-17, 75-620 Koszalin, Poland \\ ${ }^{2}$ Electrobright, 142 W. Main St., Macungie, PA 18062, USA \\ *E-mail address: Tadeusz.Hryniewicz@tu.koszalin.pl
}

\begin{abstract}
The paper aims to present the main objectives for using magnetic fields to improve process of electropolishing (EP), firstly by focusing on materials and electrochemical systems. The general introduction has been concerned on the sample surface treated under pseudopassivity conditions, in the process generally known as magnetoelectropolishing (MEP). Long-term up-to-date experiments have shown profound changes observed on metals and alloys. The advantageous effects gained by applying MEP to metals and alloys cover: improvement of corrosion resistance, bio- and haemocompatibility, roughness by modification of their surfaces. The improvements are also referred to the mechanical properties of metals and alloys treated by MEP namely: removal of hydrogen, fatigue resistance enhancement, etc. Further developments and the effects of magnetic fields on electropolishing of metals and alloys are to be presented in the next publications.
\end{abstract}

Keywords: Magnetic field; Magnetoelectropolishing MEP; Materials; Electrochemical systems

\section{INTRODUCTION}

The influence of magnetic field on electropolishing (EP) was first revealed in the Authors' works referred to metallic implants [1-4]. The US patent was released [4] and the process was named the magnetoelectropolishing (MEP). Early works, with the first recorded interest [5] in the effects of magnetic field on electrolyte solutions, were begun in the $20^{\text {th }}$ century. The studies were followed by a large number of researchers [6-13] who have contributed to this complex and challenging field. The studies were primarily focused on relating an apparent electrolyte resistivity to the strength of imposed magnetic fields [6].

Concerning the electrolyte solution viscosity, the existence of a local minimum at an intermediate magnetic field strength has been shown for the viscosity of water. The variation of viscosity with magnetic field strength cannot, however, be predicted from the fundamental relationships of physics $[6,10,11]$. Though the thermodynamics of magnetic systems have a solid theoretical foundation, there is little information available on the variation of equilibrium composition in electrolytes with the magnetic field strength. If the data for ionic equilibria in electrolyte solutions were readily available, the current understanding of 
magnetic field effects would be significantly enhanced [6]. Up-to date studies on the magnetic field effects covered mainly cathode deposits with a little reference to the anodic dissolution $[12,13]$. It is known that ions in solution are either paramagnetic, i.e. they develop a magnetic moment parallel to an imposed magnetic field, or diamagnetic, meaning the developed magnetic moment is opposed to the imposed magnetic field. The magnetic force tends to repel diamagnetic ions in a non-homogeneous magnetic field from the strong-field region, the latter attracting, in a relative sense, paramagnetic ions. Interestingly, no place in the literature is devoted to ferromagnetic ions, assuming their low importance or little meaning. While susceptibility effects are of a small magnitude, they can generate ionic movement (ion separation) under carefully designed experimental conditions. It has been underlined that the smallness of the susceptibility effect is evident with the equilibrium constant carrying a magnetic correction term of a $10^{-5}$ order of magnitude [6].

Now, instead of focusing much attention to the solution effect and investigating the inter-electrode gap, the direct effects obtained on anode or workpiece surface after MEP are researched [14-51]. The aim of the works is to present changes in the surface film formed on the sample surface treated under pseudopassivity conditions, in the process generally known as electropolishing in the presence of a constant magnetic field (MEP). Long-term up-to-date experiments have shown profound changes observed on metals and alloys.

In this paper, a sort of introduction to materials and electrochemical systems is to be performed. Further developments and the effects of magnetic fields on electropolishing of metals and alloys are to be presented in the next publications.

\section{MATERIALS}

The main purpose of using the magnetoelectroplishing MEP was to modify surfaces of metallic parts and devices to be used for implants. Therefore not a traditional change in surface roughness after the MEP process, in comparison with that one attained after a standard electropolishing EP, should be the reason for applying the magnetic fields $[2,3]$. The main advantages are the novel passive layers with the essential modification in the composition of surface film formed. Increased corrosion resistance and improved biocompatibility are expected to be obtained after MEP [14-35, 38-48]. The question arises which metals and alloys should be treated by MEP.

The up-to-date Authors' MEP studies covered the following materials (Fig. 1):

- austenitic AISI 304 and 304L stainless steels [30, 47, 51]

- austenitic AISI 316 and 316L stainless steels [14, 17-19, 22-24, 27-29, 32, 39, 40, 45, 47, 48]

- duplex LDX 2101 steel $[45,48]$

- ferritic AISI 430 steel $[37,48]$

- high alloy 4H13 steel [38]

- carbon steel C45 [48, 49]

- Co-Cr alloy known as M-605 [16]

- Niobium [42-44]

- Tantalum $[1,2]$

- CP Titanium Grade 2 [1, 2, 20, 26, 31, 33-35, 47, 49]

- Nitinol (NiTi alloy) [1-3, 15, 20, 34, 35, 47, 49, 50]

- other titanium alloys (TNZ) and Ti2448 (under investigation). 

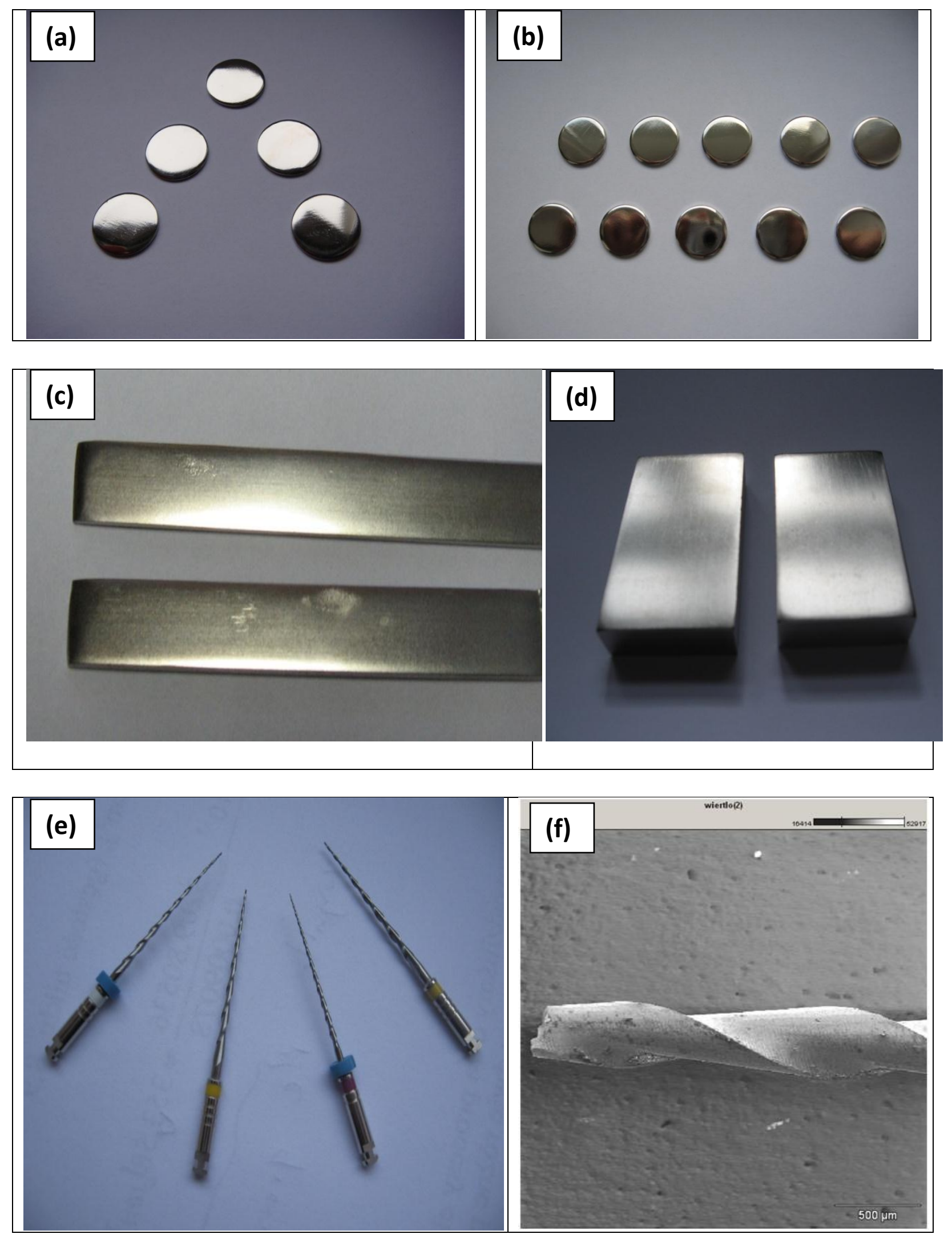

Fig. 1. Examples of samples used for the studies: (a) AISI $316 \mathrm{~L}$ stainless steel $\phi 10 \times 1 \mathrm{~mm}$, (b) AISI 316L stainless steel $\phi 20 \times 2 \mathrm{~mm}$, (c) stripes/plates CP Ti Grade 2, (d) titanium blocks, (e) Nitinol endodontic files - new tools AR, (d) used/broken file. 
Most of them are paramagnetic but $430,4 \mathrm{H} 13$, and C45 are ferromagnetic materials [37, $38,48]$. The preliminary studies indicate that ferromagnetic materials should not be treated by MEP due to worsening the surface properties obtained after the process [48]. The samples used for the studies were in the form of discs (stainless steels - see Fig. $1 \mathrm{a}, \mathrm{b}$ ), rectangular plates or blocks (austenitic stainless steels, ferritic and carbon steels, titanium - see Fig. $1 \mathrm{c}$, d), wires (Nitinol), tubes (Nitinol, austenitic AISI 304L steel), or endodontic tools (see Fig. 1 e, f).

\section{ELECTROCHEMICAL SYSTEMS}

The experiments on the materials were performed both under a standard electropolishing process in still electrolyte (EP), with a moderate mixing (MIX), and/or in the presence of a constant magnetic field in the process named magnetoelectropolishing (MEP). The main purpose was to modify chemical, physical, and mechanical properties of treated material and compare the results obtained. Both as-received (AR) and/or mechanically polished (MP) samples were used for reference. For the experiments, two kinds of magnets were used: flat disc magnets presented in Fig. 2 as-mounted, and/or ring magnets, presented below.

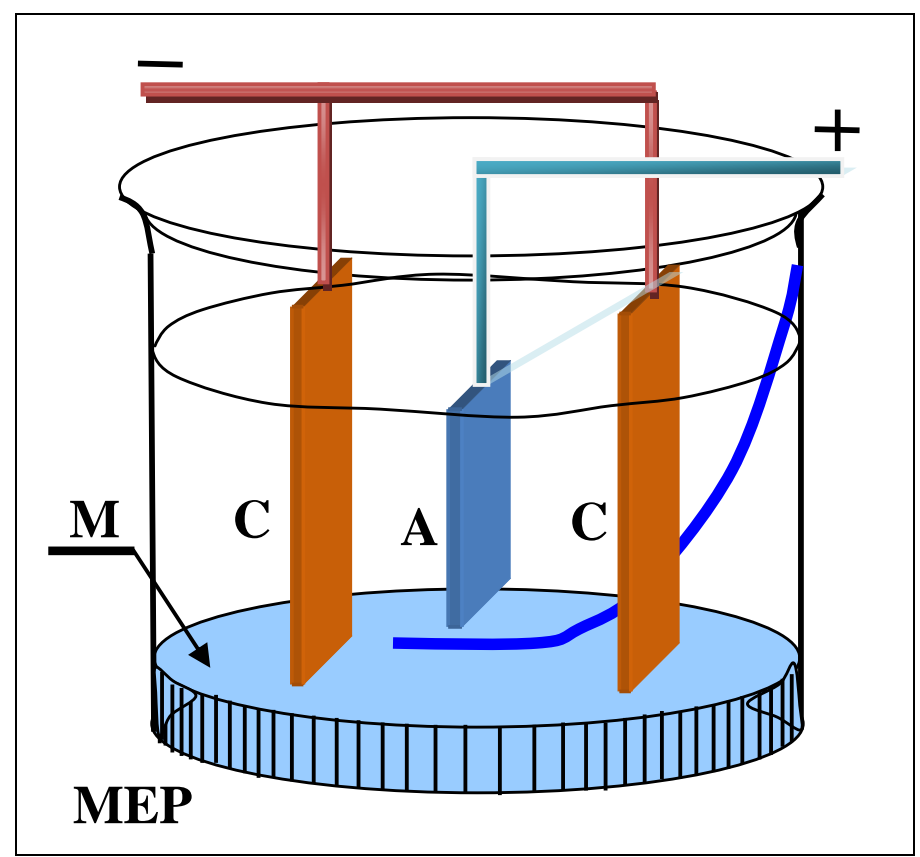

Fig. 2. Electrochemical cell with a flat magnet $\mathrm{M}$ used: $\mathrm{A}$ - anode, $\mathrm{C}$ - cathode. Magnetic field intensity marked by a blue line.

The main characteristics of the flat magnets used is given in Fig. 3, with consecutive levels of the magnetic field intensity $B, \mathrm{mT}$, dependent on the distance $x, \mathrm{~mm}$, counted from the surface of the magnet and taken under consideration in our studies. Levels presented in Fig. 3 correspond with the field intensity studied [48]. This way, by choosing each of the levels, an optimum of the magnetic field intensity could be investigated. 


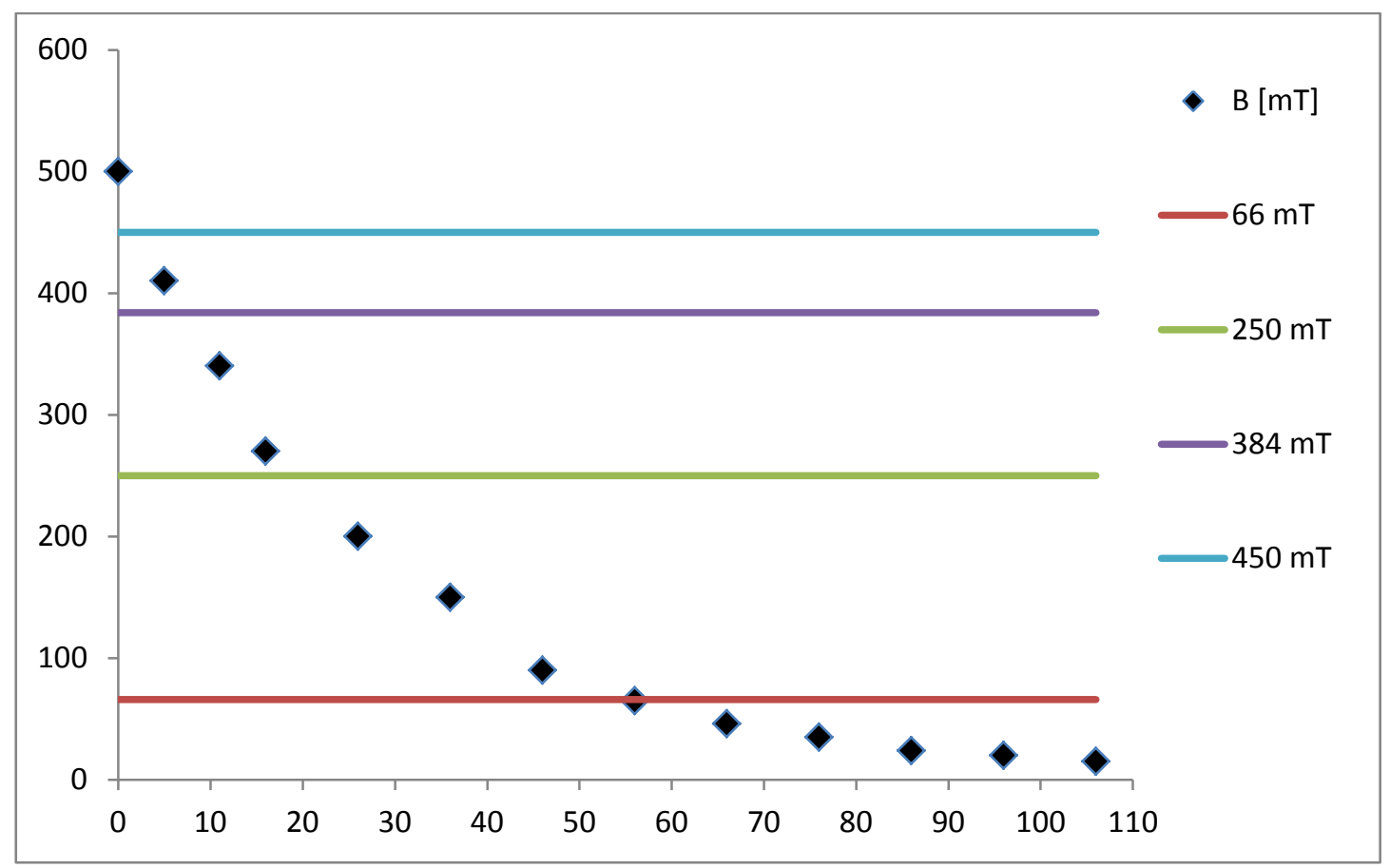

Fig. 3. Levels of the magnetic field intensity $B, \mathrm{mT}$, dependent on the distance $x, \mathrm{~mm}$, from the flat magnet surface.

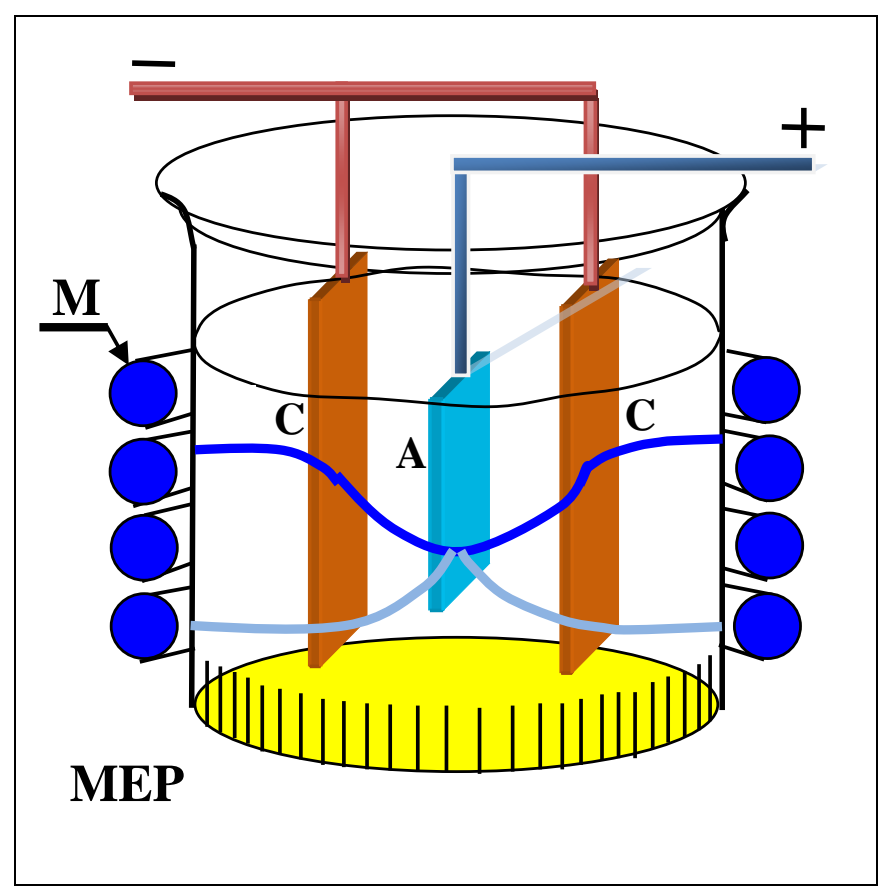

Fig. 4. Electrochemical cell with ring magnets $\mathrm{M}$ used: $\mathrm{A}$ - anode, $\mathrm{C}$ - cathode. Magnetic field intensity marked by a blue line.

Some of the samples were treated in the electrochemical system presented in Fig. 4. Ring magnets were used for the MEP process with the magnetic field intensity as-measured in 
the middle of the cylindrical cell equal to about $100 \mathrm{mT}$. The relative change in the magnetic field intensity is shown by a blue curve (see Figs. 2 and 4).

Our up-to-date research works have shown the influence of the MEP process on many mechanical properties [1-3, 20, 21, 26, 31, 39, 41, 45-47], increase in corrosion resistance $[14-21,24-26,30,32,45,46,48-50]$, decrease in hydrogenation [28, 33], improvement in biocompatibility $[1,3,14-16,18-21,26,34,46]$ of metallic materials used in medicine. Besides, the new electrolytes have been developed to electropolishing of titanium, tantalum, and cobalt alloys [1-4], niobium [42-44]. The new theory "enhanced oxidation-dissolution theory" was proposed to amend the most recognized Hoar theory of electropolishing [35, 5254]. To develop our experiments carried out at high current density and high-rate electrochemical conditions under increased temperatures, the new reference electrode was applied with the characteristics presented in Fig. 5. For this purpose, the stainless steel electrode was proved to be useful (see the characteristics of mercury-mercurious sulfate electrode MSE against austenitic 316L stainless steel electrode, Fig. 5) [48].

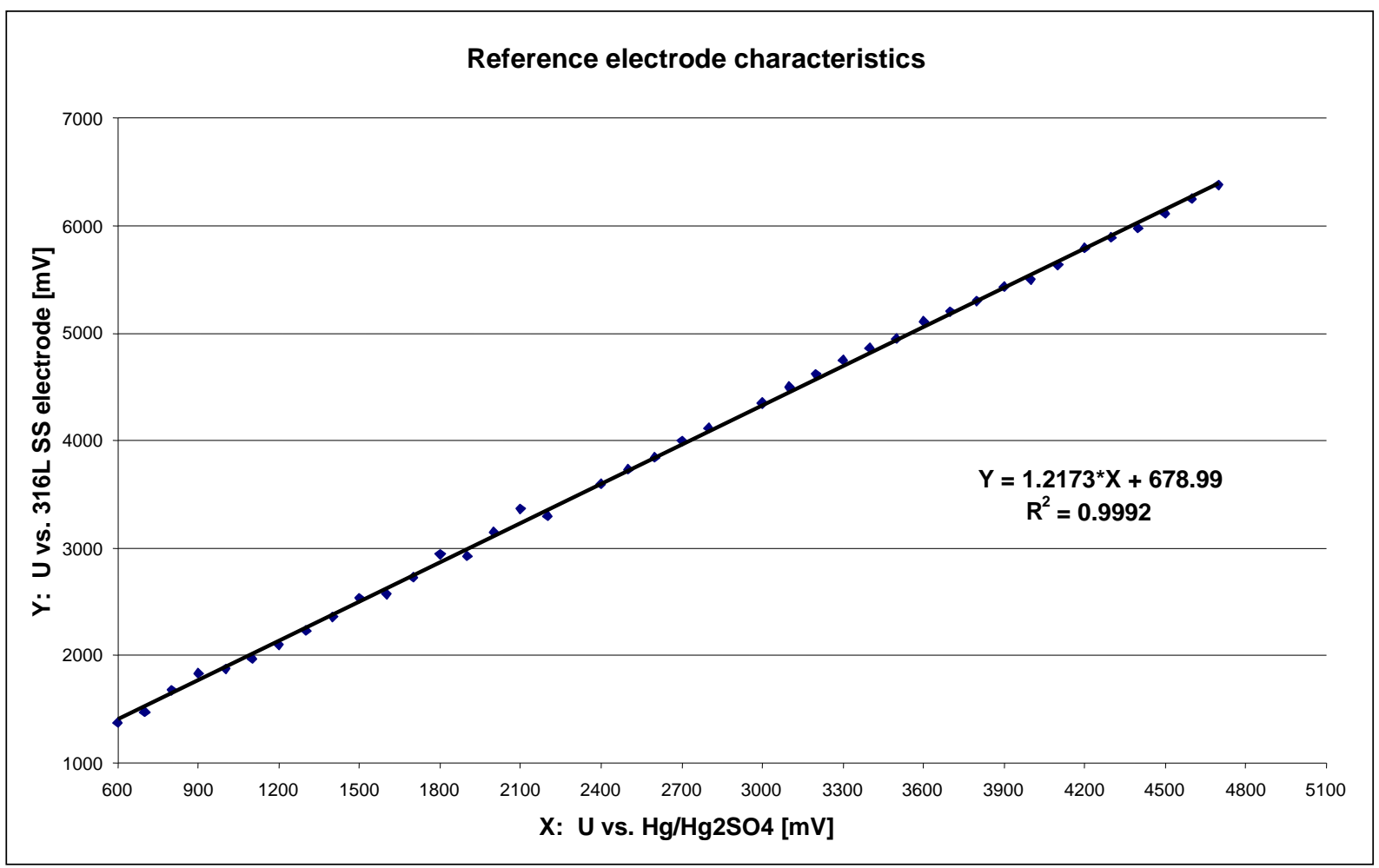

Fig. 5. The comparison of reference electrodes characteristics: MSE against AISI $316 \mathrm{~L} \mathrm{SS}\left(\mathrm{R}^{2}\right.$ is a coefficient of determination).

It should be stressed out the helpfulness and indispensability of using the advanced instrumental techniques such as AES (Auger Electron Spectroscopy), and XPS (X-ray Photoelectron Spectroscopy) to analyze the samples' most outer layer - the oxide film which physicochemical properties are of paramount significance to the metallic material performance. The view on an XPS apparatus used for the study of surface film formed after EP and MEP is shown in Fig. 6. 


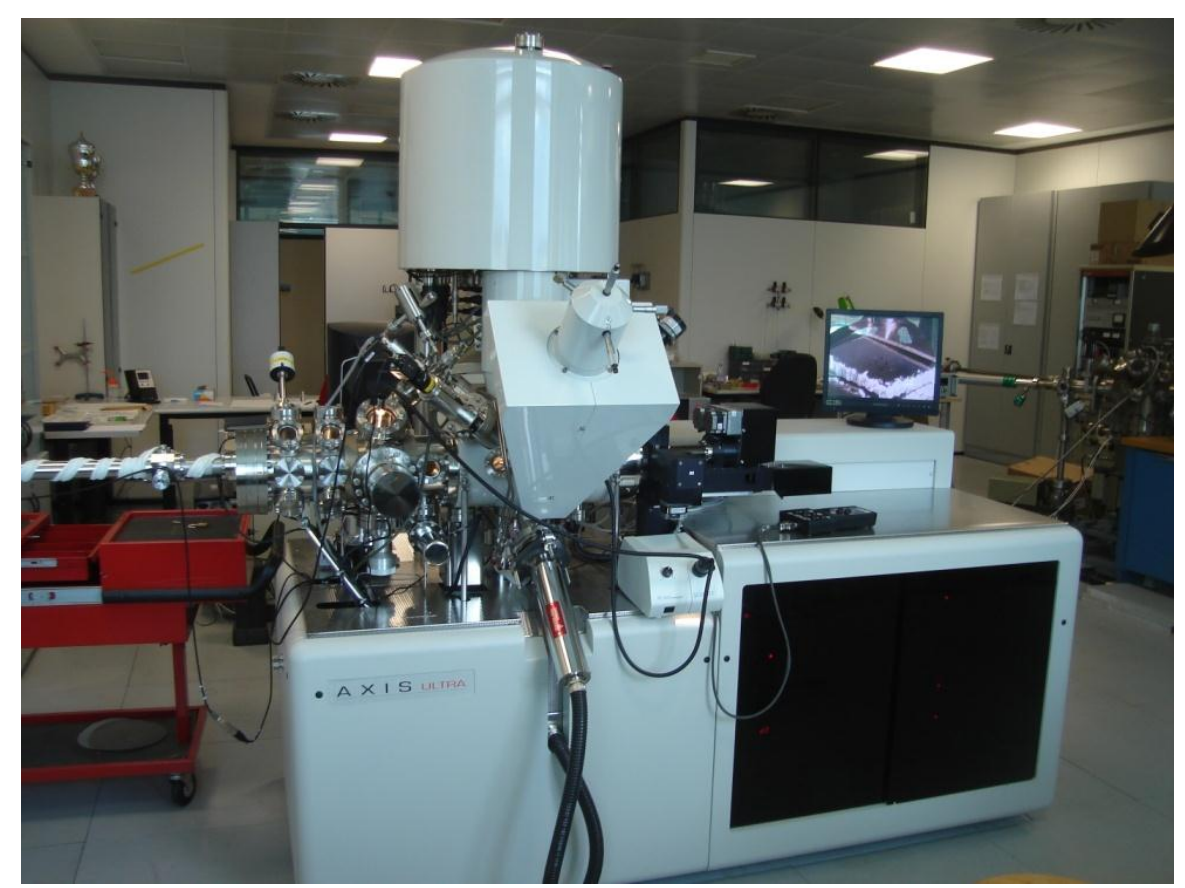

Fig. 6. View on XPS instrument used for the study of surface film formed after EP and MEP.

\section{CONCLUSION}

In one of the works [6] on the role of magnetic fields in electrochemical systems one may read: "In spite of the continual growth of information on multifaceted phenomena in electrolytic systems under the influence of magnetic fields, the exact role of magnetism in modifying microscopic as well as macroscopic behavior is not completely understood." The Authors of this paper totally agree with this statement and will try to contribute more work in the direction of better understanding of the influence of applied magnetic field on the electrolysis process specially dissolution phenomenon.

\section{References}

[1] Ryszard Rokicki, Medical Device \& Diagnostic Industry 28(3) (2006) 1-6.

[2] Tadeusz Hryniewicz, Ryszard Rokicki, Krzysztof Rokosz, Metal Finishing 104(12) (2006) 26-33.

[3] Ryszard Rokicki, Tadeusz Hryniewicz, Krzysztof Rokosz, Medical Device \& Diagnostic Industry 30(1) (2008) 102-111.

[4] Ryszard Rokicki, (2009) US Patent Nr 7632390.

[5] M. Faraday, Diary, Vol. 4, pp. 288, 7706-7721, Bell and Sons, London, 1933.

[6] T. Z. Fahidy, The Effect of Magnetic Fields on Electrochemical Processes, pp. 333-354, in Moderns Aspects of Electrochemistry, no. 32, ed. by B.E. Conway, J.O’M. Bockris, and R.E. White, Kulwer Academic Publishers, New York, Boston, Dordrecht, London, Moscow, 2002. 
[7] S. Mohanta, T. Z. Fahidy, Can. J. Chem. Eng. 50 (1972) 248.

[8] G. Dash, W. W. King, J. Electrochem. Soc. 119 (1972) 51.

[9] P. Fricoteaux, A. Olivier, R. Delmas, J. Electrochem. Soc. 139 (1992) 1096.

[10] M. Waskaas, Acta Chem. Scand. 50 (1996) 525.

[11] Z .H. Gu, J. Chen, T. Z. Fahidy, Electrochim. Acta 38 (1993) 2631.

[12] G. Hinds, et al., J. Phys. Chem. B 105(39) (2001) 9487-9502.

[13] C. Wang, S. Chen, J. Serb. Chem. Soc. 66(7) (2001) 477-481.

[14] Tadeusz Hryniewicz, Ryszard Rokicki, Krzysztof Rokosz, Transactions of the Institute of Metal Finishing 85(6) (2007) 325-332.

[15] Ryszard Rokicki, Tadeusz Hryniewicz, Transactions of the Institute of Metal Finishing 86(5) (2008) 280-285.

[16] Tadeusz Hryniewicz, Ryszard Rokicki, Krzysztof Rokosz, Materials Letters 62 (2008) 3073-3076.

[17] Tadeusz Hryniewicz, Ryszard Rokicki, Krzysztof Rokosz, Surface \& Coatings Technology 202(9) (2008) 1668-1673.

[18] Tadeusz Hryniewicz, Ryszard Rokicki, Krzysztof Rokosz, CORROSION (The Journal of Science and Engineering), Corrosion Science Section 64(8) (2008) 660-665.

[19] Tadeusz Hryniewicz, Krzysztof Rokosz, Ryszard Rokicki, Corrosion Science 50(9) (2008) 2676-2681.

[20] Tadeusz Hryniewicz, Krzysztof Rokosz, PAK (Measurement Automation and Monitoring) 55(4) (2009) 247-250.

[21] Tadeusz Hryniewicz, Ryszard Rokicki, Krzysztof Rokosz, Surface \& Coatings Technology 203(10-11) (2009) 1508-1515.

[22] Tadeusz Hryniewicz, Krzysztof Rokosz, Surface \& Coatings Technology 204 (16-17) (2010) 2583-2592.

[23] Tadeusz Hryniewicz, Krzysztof Rokosz, Materials Chemistry and Physics 122 (2010) 169-174.

[24] Krzysztof Rokosz, Tadeusz Hryniewicz, CORROSION - The Journal of Science and Engineering 66(3) (2010) 035004-1...11 (11 pages).

[25] Tadeusz Hryniewicz, Krzysztof Rokosz, Materials Chemistry and Physics 123 (2010) $47-55$.

[26] Tadeusz Hryniewicz, Ryszard Rokicki, Krzysztof Rokosz, Chapter 11. Magnetoelectropolished Titanium Biomaterial, in Biomaterial / Book 2, ISBN 978953-308-118-2, InTech, 227-248 (Edited by Rosario Pignatello), 2011, 227-248; website: http://www.intechweb.org/, http://www.intechopen.com/articles/show/title/magnetoelectropolished-titaniumbiomaterial

[27] Krzysztof Rokosz, PAK (Measurement Automation and Monitoring) 57(5) (2011) 563567 
[28] Tadeusz Hryniewicz, Piotr Konarski, Krzysztof Rokosz, Ryszard Rokicki, Surface \& Coatings Technology 205 (2011) 4228-4236.

[29] Tadeusz Hryniewicz, Krzysztof Rokosz, Victor Micheli, PAK (Measurement Automation and Monitoring) 57(6) (2011) 609-61.4

[30] Krzysztof Rokosz, Tadeusz Hryniewicz, Ochrona przed Korozja 54(7) (2011) 487-491.

[31] Tadeusz Hryniewicz, Krzysztof Rokosz, Jan Valíček, Ryszard Rokicki, Materials Letters 83 (2012) 69-72.

[32] Krzysztof Rokosz, Tadeusz Hryniewicz, Steinar Raaen, Steel Research International 83 (2012) 1-9.

[33] Tadeusz Hryniewicz, Piotr Konarski, Ryszard Rokicki, Jan Valíček, Surface \& Coatings Technology 206 (2012) 4027-4031.

[34] Ryszard Rokicki, Waseem Haider, Tadeusz Hryniewicz, Journal of Materials Science: Materials in Medicine 23 (2012) 2127-2139.

[35] Ryszard Rokicki, Tadeusz Hryniewicz, Transactions of the Institute of Metal Finishing 90(4) (2012) 188-196.

[36] Tadeusz Hryniewicz, Krzysztof Rokosz, Hugo Ricardo Zschommler Sandim, Applied Surface Science 263 (2012) 357-361.

[37] Krzysztof Rokosz, Tadeusz Hryniewicz, Steiner Raaen, PAK (Measurement Automation and Monitoring) 58(1) (2012) 126-129.

[38] Krzysztof Rokosz, Tadeusz Hryniewicz, Steinar Raaen, PAK (Measurement Automation and Monitoring) 58(6) (2012) 545-548.

[39] Krzysztof Rokosz, Tadeusz Hryniewicz, Jan Valíček, Marta Harničárová, Michel Vyležík, PAK (Measurement Automation and Monitoring) 58(5) (2012) 460-463.

[40] Krzysztof Rokosz, Tadeusz Hryniewicz, Advances in Materials Science 34(4) (2012) 13-22.

[41] Tadeusz Hryniewicz, Jan Valíček, Ryszard Rokicki, Krzysztof Rokosz, Hardness and Nanohardness Measurements of Titatnium Biomaterial after Magnetoelectropolishing, Proc. $20^{\text {th }}$ Intern. Confer. on Composite/Nanoengineering prep. for ICCE-2012, Beijing, China, July 22-28, 2012, (2-page paper)

[42] Tadeusz Hryniewicz, Krzysztof Rokosz, Jan Valíček, Hugo Ricardo Zschommler Sandim, Steinar Raaen, Niobium Surface Studies after HF-free Electrochemical Treatment, Proc. $20^{\text {th }}$ Intern. Confer. on Composite/Nanoengineering ICCE-20, Beijing, China, July 22-28, 2012, (2-page paper)

[43] Tadeusz Hryniewicz, Krzysztof Rokosz, Hugo Ricardo Zschommler Sandim, Applied Surface Science 263 (2012) 357-361.

[44] Tadeusz Hryniewicz, Krzysztof Rokosz, Applied Surface Science 265 (2013) 931-934.

[45] Krzysztof Rokosz, Tadeusz Hryniewicz, International Journal of Materials Research (former: Zeitschrift für METALLKUNDE), (2013) 1-10; http://www.ijmr.de/ MK110984 
[46] Tadeusz Hryniewicz, Krzysztof Rokosz, Correlation of Corrosion Resistance and Nanoindentation Results of AISI 316L SS Biomaterial after Surface Finishing Operations, Book of Abstracts, Corrosion Mechanisms and Methods, Eurocorr 2013, 15 September 2013, Paper No 1804, page 282.

[47] Tadeusz Hryniewicz, Krzysztof Rokosz, Jan Valiček, Ryszard Rokicki, Marta Harničarova, Michel Vyležik, PAK (Measurement Automation and Monitoring) 59(7) (2013) 676-679.

[48] Krzysztof Rokosz, Electrochemical polishing of steels in the magnetic field (in Polish), Politechnika Koszalińska Editorial House, Koszalin, 2012 (210 pages).

[49] Tadeusz Hryniewicz, Krzysztof Rokosz, Magnetoelektropolerowanie: stan badań 2012, (in Polish), Mater. SNOE (Scientific School of Electroerosive Treatment), Warsaw, 2012 (8 pages).

[50] C. Praisarnti, J. W. W. Chang, G. S. P. Cheung, Journal of Endodontics 36(8) (2010) 1354-1357.

[51] Krzysztof Rokosz, Tadeusz Hryniewicz, AUTOBUSY 5 (2013) 233-236.

[52] Tadeusz Hryniewicz, Materials Chemistry and Physics 15(2) (1986) 139-154.

[53] Tadeusz Hryniewicz, Zdzisław Hryniewicz, Journal of the Electrochemical Society 136(12) (1989) 3767-3769.

[54] Tadeusz Hryniewicz, Surface \& Coatings Technology 64(2) (1994) 75-80.

(Received 24 November 2013; accepted 29 November 2013)

\section{Biography}

\begin{tabular}{|l|l|}
\hline & $\begin{array}{l}\text { Full Professor Tadeusz HRYNIEWICZ, DSc PhD ME CE } \\
\text { Graduated at Faculty of Mechanical Engineering of Szczecin University of } \\
\text { Technology (1968). Completed industrial training (1968-71) in ceramic } \\
\text { industry; obtained PhD (1979). He has got the Fulbright allowance, } \\
\text { completed studies at Chemical Engineering Faculty, University of } \\
\text { California, Berkeley, and made a research work at Lawrence Berkeley } \\
\text { Laboratory (1980-81). PhD and DSc degrees got from Wrocław University } \\
\text { of Technology. Associate Editor to four scientific international journals. } \\
\text { Scientific interests: electrochemical corrosion, surface electrochemistry, } \\
\text { metallic biomaterials, magnetoelectropolishing. } \\
\text { E-mail: Tadeusz.Hryniewicz@tu.koszalin.pl }\end{array}$ \\
\hline
\end{tabular}




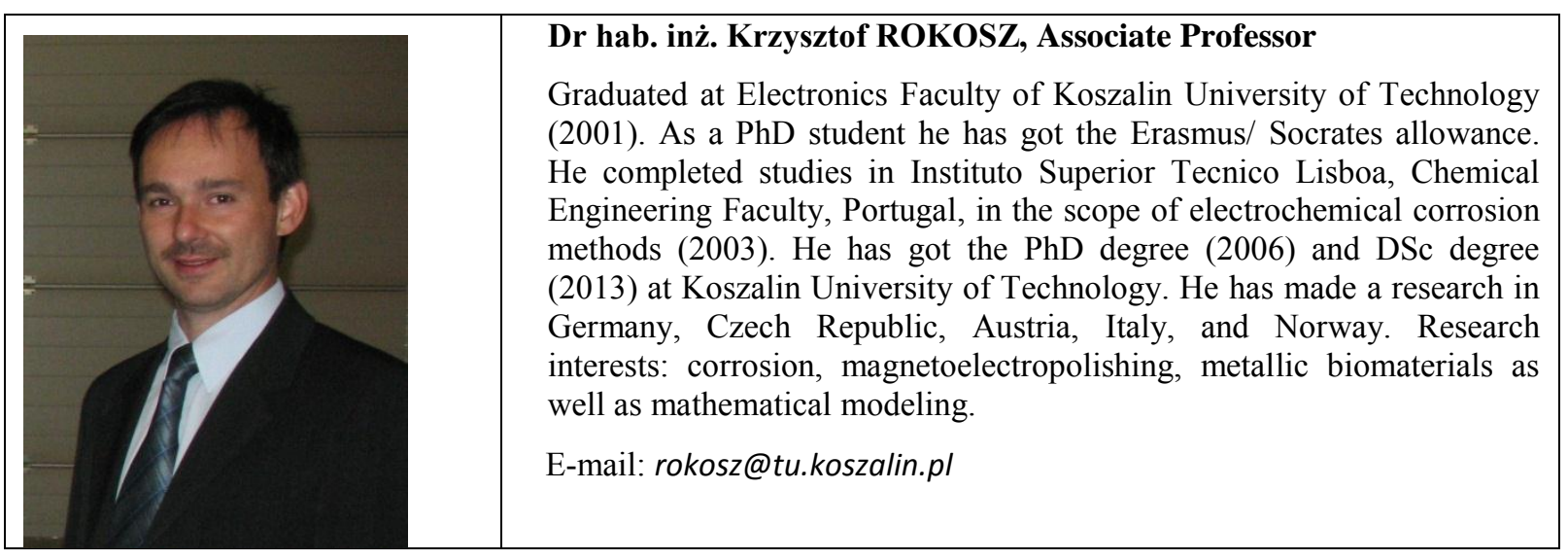

\begin{tabular}{|l|l|}
\hline & $\begin{array}{l}\text { Mgr inż. Ryszard Rokicki, MSc } \\
\text { Graduated at Faculty of Water Protection and Inland Fishery of } \\
\text { Agricultural-Technical Academy of Olsztyn (1980). After emigration to } \\
\text { USA (1984) he opened the industrial electropolishing shop } \\
\text { ELECTROBRIGHT, Macungie PA, in 1988 which he operates at the } \\
\text { present time. He invented patented (US Patent 7632390) electropolishing } \\
\text { process in magnetic field, namely "magnetoelectropolishing". Research } \\
\text { interests: magnetoelectropolishing, improvement of biocompatibility and } \\
\text { fatigue resistance of metallic implants (stents, heart valves, etc.). } \\
\text { E-mail: ryszardr@ptd.net }\end{array}$ \\
\hline
\end{tabular}

